\title{
Education System of the World: Modern Trends
}

Safiullin N.Z.

Kazan Federal University, Kazan, 420008, Russia

Gafurov I.R.

Kazan Federal University, Kazan, 420008, Russia

Safiullin L.N.

Kazan Federal University, Kazan, 420008, Russia

Email address: lenar_s@mail.ru.

Odintsova J.L.

Kazan Federal University, Kazan, 420008, Russia

\section{Doi:10.5901/mjss.2014.v5n18p91}

\section{Abstract}

Global educational environment brings together national education systems of different types and levels vary considerably in philosophical and cultural traditions, the level of goals and objectives, its qualitative state. Therefore, we should talk about today world educational space as forming a single body in the presence of each educational system of global trends and maintaining diversity. Studied issues of the growing importance of intellectual work, based on the use of information resources on a global scale and the need for the implementation of operational communications between individual professionals, social and professional groups, communities, individuals, community organizations and states. Considers the role of information and communication in the development of society and the mechanisms for creating a single global information space within the world of education. Substantiates the competence to find information and use it in their work, to give a professional assessment of information requirements to the expert any profile.

Keywords: individual professionals, intellectual work, information technology, professional assessment.

\section{Introduction}

The world community of the beginning of the third millennium is characterized by a number of features to which it is necessary to refer, first of all, increased importance of intellectual work focused on use of information resource of global scale and requirement for implementation of expeditious communication between certain experts, social and professional groups, communities of people, public organizations and the states. The role of information and communications in society development always was considerable, and the break made in the sphere of information and telecommunication technologies, allowed to unite the computers which are in various points of the world in one Network. As a result society started creation of uniform world information space, or, world information resources [1, 3-5].

The most important elements of electronic part of world information space are professional bases, business resources the Internet, electronic libraries. Increase of a role of information product as the tendency of development of information society defines need for processing of escalating volumes of information, need for various forms of perception of information, and also need for relevance and information accuracy. Ability to find necessary information and to use it in the activities - the obligatory requirements applicable to expert of any profile. The modern expert has to be able:

- to define information requirements for the solution of a specific objective;

- to use information resources taking into account existing legislative and ethical standards;

- to get access to information resources;

- to give a professional assessment of information;

- to use information found in world resources at the solution of professional tasks. 
In information society the special attention is paid to information resources and their importance is emphasized in comparison with traditional types of resources [2, 8-11]. In spite of the fact that information resources always existed, they weren't considered earlier (in the conditions of industrial society) neither as economic, nor as other category. Information resource can belong to one person or a group of persons, organization, city, region, country, the world.

The international non-governmental organization of standardization International Organization for Standardization (ISO) founded in 1947 in the ISO 15836:2003 standard * defines information resource as something having distinctive feature (anything that has identity) thanks to which this essence can be allocated in independent quality. Thus makes a reservation that usually IR is the electronic document $[5,11]$.

IEEE [Institute of Electrical and Electronics Engineers] Institute of engineers on electrical equipment and electronics (the professional association, issuing own standards; members of IEEE are ANSI and ISO) is the organization founded in 1963 in the USA and establishes standards for computer facilities and communication. In them concept IR is replaced with the concept "educational object" (learning object) - digital or non-numerical essence which can be used in the educational purposes. Thus, the uniform model for systematization of information essences (any kinds and forms), material objects, personnel resources and the events relating to education is entered. And, respectively in Learning Object Metadata standard. - New York: IEEE, 2002 IR is defined as the document (set of documents), intended and independently issued for distribution among an unlimited circle of people or forming a basis for representation of information services.

Thus, according to all listed sources, information resources are the knowledge prepared by people for social use in society and recorded on the material carrier. Information resources of society if to understand them as knowledge, are aloof from those people who accumulated them, generalized, analyzed, created, etc. This knowledge materialized in the form of documents, databases, knowledge bases, algorithms, computer programs, and also works of art, literature, science. Now it isn't developed certain methodology of quantitative and quality standard of information resources, and also forecasting of requirements of society in them $[13,14]$.

If it is a question of information resources of country, region, organization, they have to be considered as the strategic resources similar on the importance to stocks of raw materials, energy, minerals and to other resources. If information resources are considered as set of information resources of various states, it is accepted to call such information resources world information resources.

\section{Result}

It is very difficult to divide world information resources into certain types (categories), but it is possible to allocate some criteria by which it is possible to carry out splitting into types.

The first criterion - according to representation form, i.e. in what form information is recorded or provided : text form; graphic form; multimedia, etc. This criterion is the most generalized and it is very easy to make splitting according to it, the long analysis of information isn't required for definition of belonging to this or that type.

The second criterion - on restriction of access or protection, here it is possible to allocate three types of information resources: data which are the state secret; personal information; data which are a trade secret. To carry this or that document to one of listed above groups it is necessary to be guided by the legislation, in all countries almost identical criteria are accepted, there are only small divergences.

The third criterion - breakdown according to subject, the most difficult criterion as these or those information resources can be carried to at once several types. Quantity of types hugely, for example: legislative resources; statistical resources; educational resources; etc. Classifications of information educational resources, as a rule, are carried out on the following bases: on purpose, on education levels, on target audience, subject, classifications by type of information resource.

Extent of integration of information technologies and world information resources in educational process can conditionally be divided into three levels:

First level. Use of various means of submission of educational information and world information resources for the solution of traditional educational tasks at new qualitative level. For example, creation of electronic manuals and practical works, application of new technologies for carrying out traditional lectures and seminars with the use of presentations, etc.

Second level. Accomplishment of educational process with the use of interactive interface of participants of educational process (technology of distance or open learning in a global network). At this level conference teleconferences, forums, electronic educational and methodical materials, etc. are used.

Third level. Solution of essentially new tasks. Use of the integrated educational environments where the main 
component are not only applied technologies, but also substantial part, i.e. information resources. The combination of modern means of informatics and information resources allows to create educational and methodical complexes of the new generation on the basis of Internet resources. At this level information technologies are used as an access to world information resources on the basis of which educational process is based. Training with the use of world information resources fills the training program with qualitatively new contents, allows to use professional information resources which are available to experts to solve real practical tasks in educational process.

Recently much attention in researches is paid to development of strategy of formation of information resources on the basis of methodical development and software created at a stage of expanded introduction of information technologies in education. Thorough development of this question is available, for example, in the monograph Robert I.V. Big actual material relating to this problem, is in works of the last conferences devoted to creation of electronic educational resources. It appears that it is possible to formulate some starting provisions for researches in this area.

1. Application of info-communication technologies (ICT) in education can be effective only in unity with pedagogical technologies.

It implies establishment of information communications between didactic units of this subject domain and modular and block structure of an electronic resource. Educational influence is carried out at the expense of purposeful contents of information and means of electronic support of individual and collective creativity.

2. The ICT transfer in other fields of knowledge has to lead to a new level of quality of education, and also to contents updating, give new opportunities for creative development of the personality.

In other words ICT do not fit to available tutorials, but organically grow into them, changing volumes of scientific knowledge, formats of representation of knowledge, and also adapting educational technology for opportunities and needs of the personality instead of what took place in a mode of "total" training.

3. The domestic pedagogical science and experience of Russian education are property which keeps its value also in information society, and can be favourably used when forming information educational resource. Following this principle has to lead to specific to our education methods and means of screen representation of knowledge, at the same time conditions of integration of our information educational environment in world information space have to be met.

4. The modern information resource has to be essentially focused on distance learning. It corresponds to the new forms of education and requirements to study during all life. It also means that absence of possibility of inclusion in collective formed information environment in the software product can testify to its unfitness for full application in educational purposes.

5. In screen representation of knowledge and modes of communication with network educational environment the major factors are indicators of efficiency of applied educational resource and measure of observance of health saving conditions. Therefore, adequate criteria of the corresponding qualities have to be developed and by these criteria it is necessary to estimate both substantial, and ergonomic properties of final development.

6. Indispensable condition of formation of information educational resource is observance of copyright and license standards. It is the question least developed today in which possible creative manners, financial factors, practice of control and replication of information materials intertwined. Unfortunately, such subject is very niggardly presented at our conferences and in publications.

7. Information educational resource needs to be based on the open (free) software. Here special comments aren't necessary as the corresponding task is set in the state scale. But there is a problem of adaptation of the rich training electronic material created for the last year, to open platforms.

8. The preference has to be given to the modular principle of creation of information materials that allows to provide variability of its application and opportunity to trace changes in education standards. Such approach appears to be the most natural for the development of the knowledge base and the expert systems which absence is quite obvious today.

9. Interactivity of an electronic information resource satisfies modern criteria of its quality and has to be provided taking into account access to it through global and domestic search engines. It actually isn't something unusual today. However, here it is important to provide timely transition of the Web 2.0 technologies, allowing to accomplish the principle of interactivity very effectively for creative searches and efforts of the user [15].

10. Creative participation of teachers, students, participants of the Academic Olympics and conferences in formation of content of educational appointment is welcomed. It is possible to say that we consider this precept rather fully, since in reports of various authors, in publications of conferences much attention is paid to this question. 


\section{Conclusion}

The exit of information technologies in various subject domains diversifies formats of screen submission of information. And always important condition is ensuring presentation with attraction of images, concepts and structures of material peculiar to this area of knowledge. Therefore educational electronic product has to be maximum degree "multimedia". Integration of information and pedagogical technologies means establishment of information communications between didactic units of this subject domain and modular and block structure of an electronic resource.

Summing up the result, it is possible to note that inclusion of modern computer and telecommunication technologies in educational process, wide use of world information resources creates possibilities of improvement of educational services quality, but at the same time demands change of contents and training methods.

\section{References}

Barbour, M., Archambault, L., DiPietro, M. K-12 Online Distance Education: Issues and Frameworks // American Journal of Distance Education 27 (1) , 2013? pp. 1-3.

Çakir, Ö., Oğuz, E. Situations of distance education institutions in Turkey // Procedia - Social and Behavioral Sciences 9, 2010, pp. 1722-1730.

Panasyuk M.V., Pudovik E.M., Sabirova M.E. Problems of labor market of modern Russia in conditions of stable economic growth. Life Science Journal 2014; 11(6s): 487 - 489.

Bagautdinova N.G, Sarkin A.V., Averyanov B.A., Arzhantseva N. The Consept of "New" Paternalism and Its Realisation within The State Regualtion of Econom// Mediterranean Journal of Social Sciences.- Vol.5, No12, (2014)-pp.27-32.

Harrison, N., Peacock, N. Cultural distance, mindfulness and passive xenophobia: Using Integrated Threat Theory to explore home higher education students' perspectives on 'internationalisation at home' // British Educational Research Journal 36 (6) , 2010, pp. 877-902.

Bagautdinova, N.G., Tsvetkova, G.S., Novenkova, A.Z. The interaction of formal and informal market institutes // World Applied Sciences Journal, 27(13), 2013, 58-61.

Bagautdinova N.G., Tsaregorodtsev E., Kulalayeva I., Arzhantseva N. Assessment of Mutual Probabilistic Influence of Volatility of Official Price for Precious Metals on the Market Value of the Bi-Currency Basket// Mediterranean Journal of Social Sciences.Vol.5, No12, (2014)-pp.33-38.

Işman, A., Işbulan, O. Usability level of distance education website (Sakarya University sample) //Turkish Online Journal of Educational Technology 9 (1) , 2010. pp. 243-258.

Karal, H., Çebi, A., Pekşen, M. Student opinions about the period of measurement and evaluation in distance education: The difficulties // Procedia - Social and Behavioral Sciences 9 , 2010. pp. 1597-1601.

Fakhrutdinova E., Severyanov O., Shigabutdinov A., Fakhrutdinov R. The crisis of 1998 in Russia: political intervention and its implications. Life Science Journal 2014; 11(6s): $442-447$.

Bagautdinova N.G, Sabitov N.H, Salakhov B.R.,. Shakhnina I.Z Regional Banks in the System of Government Regulation of Economy/l Mediterranean Journal of Social Sciences.- Vol.5, No12, (2014)-pp.39-42.

Kotsiantis, S., Patriarcheas, K., Xenos, M. A combinational incremental ensemble of classifiers as a technique for predicting students' performance in distance education // Knowledge-Based Systems 23 (6) , 2010. pp. 529-535.

$\mathrm{Li}$, P. Effect of Distance Education on Reference and Instructional Services in Academic Libraries // Internet Reference Services Quarterly 18 (1) , 2013. pp. 77-96.

Bagautdinova, N., Gafurov, I., Kalenskaya, N., Novenkova, A. The regional development strategy based on territorial marketing (The Case of Russia) // World Applied Sciences Journal, 18(Issue SPL.ISSUE. 18), 2012, 179-184.

Panasyuk M.V., Pudovik E.M., Sabirova M.E.. Optimization of regional passenger bus traffic network // Procedia Economic and finance. Volume 5, 2013. pp. 589-596.

Rovai, A.P., Downey, J.R. Why some distance education programs fail while others succeed in a global environment // Internet and Higher Education 13 (3) , 2010. pp. 141-147.

Bagautdinova N.G., Khadiullina G.N.,. Shevko N.R, Pratchenko O.V. Condition and Development Characteristics of The Russian Market of Information Technilogies// Mediterranean Journal of Social Sciences.- Vol.5, No12, (2014)-pp.21-26.

Hajullina A.D., Romadanova O.A. Technique of measurement of value of the human capital as intangible asset of corporation. Life Science Journal 2014; 11(6s): $518-521$.

Safiullin, M.R., Elstin, L.A., Shakirova, A.I.. Evaluation of business and economic activity as a short-term forecasting tool // Herald of the Russian Academy of Sciences (4), 2012. pp. 290-294. 